\title{
THREE CASES OF ACUTE MESENTERIC LYMPHADENITIS DUE TO PASTEURELLA PSEUDOTUBERCULOSIS
}

\author{
BY \\ N. S. MAIR, HÉlÈNE J. MAIR, E. M. STIRK, AND J. G. CORSON \\ From the Public Health Laboratory Service, Isolation Hospital, Leicester, and the \\ Royal Infirmary, Leicester
}

(RECEIVED FOR PUBLICATION JUNE 16, 1960)

Seventeen cases of mesenteric adenitis were investigated between May and October, 1959, for the presence of virus as well as for evidence of Pasteurella pseudotuberculosis infection.

Specimens examined included mesenteric glands, appendix, throat swab, faeces, and serum, although glands were received from only 12 patients. Virus was not isolated from any of the specimens, but evidence of infection with Pasteurella pseudotuberculosis was obtained in three patients.

The three cases of acute mesenteric lymphadenitis due to Pasteurella pseudotuberculosis are reported.

Pasteurella pseudotuberculosis Type IA was isolated from the mesenteric glands of two of the cases, and all three cases showed serological evidence of infection with the organism. The mesenteric glands of two of the cases showed histological changes characteristic of pseudotuberculosis.

Acute mesenteric lymphadenitis, mimicking appendicitis, is not uncommon in this country. Aird (1945) reports that in the Royal Hospital for Sick Children, Edinburgh, during the year 1944, there were admitted in his charge 37 patients suffering from non-specific mesenteric adenitis compared with 83 suffering from acute appendicitis and four suffering from abdominal tuberculosis. During the period May to October, 1959, of 93 children admitted for suspected appendicitis to the Leicester Royal Infirmary, 20 were found to be suffering from acute mesenteric adenitis.

Many causes have been suggested, including infection with organisms of the dysentery group (Felsen, 1935), infection with a hypothetical virus derived from the upper respiratory tract (Aird, 1945), and hyperinfestation of the intestine with roundworms (Kirthi Singha, 1959).

In 1953, Masshoff and Dölle observed certain pathological changes in the mesenteric glands of young children operated on for suspected appendicitis. At operation the appendix was found to be normal or only slightly inflamed while the ileocaecal glands were enlarged. The changes in the glands were characterized by the formation of one or more follicles consisting mainly of reticulum cells. Because of the tendency of the follicles to undergo necrosis the authors described the pathological process that they had observed as an "abscess-forming reticulocytic lymphadenitis," and suggested that it might be of viral origin, since the histological changes in the affected glands resembled those found in cat-scratch fever and lymphogranuloma inguinale. In the following year, however, Knapp (1954) and Knapp and Masshoff (1954) reported the isolation of Past. pseudotuberculosis from the enlarged mesenteric glands of two children operated on for appendicitis. In both cases the appendix was normal. The histological changes in the glands were identical with those described by Masshoff and Dölle. From then until 1957, 117 cases of Past. pseudotuberculosis were diagnosed by Knapp and his co-workers at the Hygiene-Institut in Tübingen (Knapp, 1958).

Early in 1959 Dr. G. S. Wilson drew our attention to the work of Knapp and his colleagues, and as we were already making an investigation into the possible viral origin of mesenteric adenitis, it was decided to include Past. pseudotuberculosis in the scope of our inquiry.

Arrangements were made to collect glands, appendix, faeces, throat swab, and serum from each patient. In the six months from May, 1959, we received the full complement of specimens from 12 patients, and from five others all the material with the exception of the glands. Bacteriological and histological examinations were made of the glands and appendices, and the 
sera were examined for antibodies to Past. pseudotuberculosis. Frozen glands, faeces, and throat swabs were cultured for viruses on amnion and MK2 cells-a continuous monkey kidney cell line (Westwood, Macpherson, and Titmuss, 1957).

We were unable to isolate viruses from any of the specimens examined. On the other hand, we were able to find evidence of infection with Past. pseudotuberculosis in three of the 12 children from whom both gland and serum were received. There was no serological evidence of infection with the bacterium in the other five patients.

We report here the three cases of pseudotuberculous mesenteric lymphadenitis. As far as we are aware they are the first to be recorded in this country.

\section{Case Reports}

Case 1.- R. Sturgeon, a boy aged 10, was admitted to the Leicester Royal Infirmary on May 11, 1959, with a five-day history of central abdominal pain, described as a dull ache. He had had similar attacks previously, but never one so long or so severe as the present one. He felt sick during the iilness but did not vomit. He also had mild diarrhoea of two days' duration.

On examination the temperature was $99.8^{\circ}$ and the pulse rate 88 . There was tenderness and guarding in the right iliac fossa. The rebound sign was equivocal. No masses were felt in the abdomen nor was anything abnormal detected per rectum. The absence of vomiting made the diagnosis somewhat uncertain, but since there appeared to be more tenderness in the right iliac fossa than in the left an appendicectomy was performed.

Operation (May 11).-A normal retrocaecal appendix was present. There was no Meckel's diverticulum. The mesenteric glands were enlarged. The appendix and a mesenteric gland were removed for examination.

Progress.-The temperature became normal on the first post-operative morning. On the second day the patient was restless and irritable, but eventually settled down. No diarrhoea occurred after the operation.

Laboratory Findings.-The mesenteric gland was about $\frac{1}{4}$ in. in diameter. No organisms were seen in the direct smears, and culture was sterile. Histological examination showed early features of Pasteurella pseudotuberculosis infection. Serum taken on May 12, the day after operation, agglutinated Pasteurella pseudotuberculosis Types IA and IB to a titre of $1: 300$. Serum taken five months later showed no agglutinins for Pasteurella pseudotuberculosis.

Case 2.-K. Schofield, a girl aged 15, was admitted to the Infirmary on May 13,1959, with abdominal pain of three days' duration. The pain, which remained localized in the umbilical region, was dragging in nature. There was no nausea or vomiting.
Appetite had been poor for three days. The patient complained of slight frequency with some suprapubic pain on micturition. She had been constipated for a week before admission. A similar attack three months previously had passed off in one week.

On examination the temperature was $102.4^{\circ}$, the pulse rate 112, and respirations 20 . She did not look ill. The tongue was clean. The abdomen was soft with no guarding. There was tenderness on the left side and right hypochondrium. The descending colon was loaded. Bowel sounds were normal. Urine, S.G. 1012, was acid, straw-coloured, without albumin, sugar, or acetone. A provisional diagnosis of mesenteric adenitis or subacute appendicitis was made.

Operation (May 13).-The appendix was mildly inflamed and not adherent. The pelvis was normal. There was no Meckel's diverticulum. The terminal ileal glands were enlarged. Appendicectomy and gland biopsy were performed.

Progress.-On the day following operation the temperature remained at $100^{\circ}$. It fell to normal on the morning of the 15 th, but rose to $100^{\circ}$ that evening. The following evening it shot up to $102^{\circ}$. On the evening of the 18th it was $101^{\circ}$ and then it fell to subnormal, and remained thus until discharge on May 20. On the day of the high fever the scar was tender, but this settled in 24 hours.

Laboratory Findings.-A direct Gram-stained smear of the gland revealed numerous Gram-negative coccobacilli. Culture yielded a profuse growth of Pasteurella pseudotuberculosis (Schofield strain). Serum taken on May 13 agglutinated the homologous organism and Pasteurella pseudotuberculosis Types IA and IB to a titre of 1:500. A second specimen of serum taken on October 17 showed no trace of agglutinins. Histological examination of the gland was not made in this case.

Case 3.-G. Burke, a boy aged 12, was sent to hospital by his practitioner on October 19, 1959, with the provisional diagnosis of mesenteric adenitis. He had a two-day history of central abdominal pain, which moved over to the right side on the day before admission. He vomited once on the night of October 18. Bowel movements and micturition were normal. He had slight nausea and anorexia. He had had no previous attacks.

On examination temperature was $101.6^{\circ}$ and pulse rate 120 . The tongue was slightly coated and moist, and foetor was present. The abdomen was not distended, but tender with muscle guarding in the right iliac fossa. There was no rebound tenderness. No masses were felt. Rectal examination revealed tenderness in the right side over the peritoneal surface. A diagnosis of acute appendicitis was made.

Operation (October 19).--The appendix looked normal. There was no Meckel's diverticulum. Appendicectomy was performed and a very large gland in the ileocaecal angle was removed.

Progress.-Apart from a slight pyrexia of $99^{\circ}$ on October 22 the boy made an uneventful recovery. 
Laboratory Findings. - No organisms were seen in the direct smears of the gland. Culture yielded Pasteurella pseudotuberculosis, and the organism was also isolated from a guinea-pig inoculated with a suspension of the gland (Burke strain). Histological examination showed the characteristic features of Pasteurella pseudotuberculosis infection. Serum taken on October 19 agglutinated the homologous organism to a titre of $1: 5,000$ and Pasteurella pseudotuberculosis Types IA and IB to a titre of $1: 3,000$. Opportunity was taken to study the decline in agglutinins in this patient and the results are described later in the section on serology.

\section{Bacteriology}

Examination of Mesenteric Glands.-Each gland was examined as follows: Smears were stained by Gram's method and by a modified acid-fast technique recommended by Cook (1952) for the recognition of Pasteurella pseudotuberculosis in tissues. The gland from Case 2 was the only one to show Gram-negative and acid-fast bacilli in the smears.

The gland was then ground up in $5 \mathrm{ml}$. digest broth, and loopfuls of the suspension were inoculated on $5 \%$ horse-blood digest agar and into digest broth. Duplicate cultures were incubated at $22^{\circ} \mathrm{C}$. and $37^{\circ} \mathrm{C}$. for 48 hours. The Schofield strain was obtained on direct culture at $37^{\circ} \mathrm{C}$. On the other hand, Burke's strain was isolated only after preliminary incubation in broth at $22^{\circ} \mathrm{C}$. for 24 hours.

Guinea-pig inoculation was carried out only with Burke's gland suspension. The animal became ill on the seventeenth day after inoculation and was killed on the twentieth day. At necropsy there was a large caseating abscess at the site of injection, caseous enlargement of the regional gland, and generalized septicaemic spread with multiple nodules in the liver, spleen, and lungs. Pasteurella pseudotuberculosis was isolated in large numbers from the local lesion, organs, and heart blood.

Examination of the Appendix.-The interior of each appendix was exposed and inoculated on blood agar plates, which were incubated at $22^{\circ} \mathrm{C}$. and $37^{\circ}$ C. and examined after 24 and 48 hours with negative results for pasteurella.

Identification of Schofield and Burke Strains.Both strains showed similar morphological, cultural, and biochemical characteristics. Both consisted of Gram-negative cocco-bacilli, motile in broth culture at $22^{\circ} \mathrm{C}$. and non-motile at $37^{\circ}$ C. They grew readily on the usual media, producing on blood agar, after 24 hours at $37^{\circ} \mathrm{C}$., flat, dry, non-haemolytic colonies, with crenated edges and a dull granular surface. After 24 hours' incubation at $22^{\circ} \mathrm{C}$., small moist colonies with entire edge and smooth shining surface were produced. Colonies grown at $37^{\circ}$ tended to agglutinate spontaneously in normal saline, in contrast with those grown at $22^{\circ} \mathrm{C}$. which showed no tendency to auto-agglutination. Minute colonies appeared on MacConkey's medium after 24 hours at $37^{\circ} \mathrm{C}$. In broth growth was diffuse at $22^{\circ} \mathrm{C}$., and tended to be more viscous at $37^{\circ} \mathrm{C}$.

Acid without gas was produced after 18 hours at $37^{\circ} \mathrm{C}$. in dextrin, glucose, laevulose, maltose, mannitol, rhamnose, and trehalose, after 48 hours in galactose and glycerol, and after four days in salicin. Trace reactions were obtained in sorbitol and xylose. Arabinose, dulcitol, inulin, lactose, raffinose, and sucrose were not fermented after 14 days.

The methyl-red reaction was positive and the Voges-Proskauer reaction negative. Indole and $\mathrm{H}_{2} \mathrm{~S}$ were not produced and gelatin was not liquefied. Urea was decomposed, litmus milk was rendered alkaline, and nitrates were rapidly reduced. Catalase was present.

Guinea-pigs injected intramuscularly with 0.5 $\mathrm{ml}$. of 24-hour broth cultures of the Schofield and Burke strains died in nine and 18 days respectively. Post-mortem findings were similar to those obtained with Burke's infected gland suspension.

\section{Serology}

Strains of seven serotypes and subtypes of Pasteurella pseudotuberculosis were obtained from the National Collection of Type Cultures. The antigenic constitution of the different types is shown in Table I.

\section{TABLE I}

ANTIGENIC CONSTITUTION OF PAST. PSEUDOTUBERCULOSIS ACCORDING TO KNAPP (1956)

\begin{tabular}{|c|c|c|c|c|}
\hline Type & Subtype & Somatic & ntigen & Flagellar Antigen \\
\hline $\begin{array}{r}\text { I } \\
\text { II } \\
\text { III } \\
\text { IV } \\
\text { V }\end{array}$ & $\begin{array}{l}\text { IA } \\
\text { IB } \\
\text { IIA } \\
\text { IIB }\end{array}$ & $\begin{array}{rr}1 & 2 \\
1 & 2 \\
1 & 5 \\
1 & 5 \\
1 & 8 \\
1 & 9 \\
1 & 10\end{array}$ & $\begin{array}{l}3 \\
4 \\
6 \\
7\end{array}$ & $\begin{array}{l}\mathbf{a} \\
\mathbf{a} \\
\mathbf{a} \\
\mathbf{a} \\
\mathbf{a} \\
\mathbf{b} \\
\mathbf{a}\end{array}$ \\
\hline
\end{tabular}

Living suspensions were used throughout for agglutination tests as recommended by Knapp (1956), who reported that heat-killed $\left(100^{\circ}\right.$ C.) antigen was not agglutinated by human antisera. Agglutinating antigen was prepared by growing the organism on tryptose agar at $22^{\circ} \mathrm{C}$. After 48 hours the growth was harvested in normal saline, centrifuged, resuspended in saline, agitated with glass beads in a shaker for 20 minutes, and finally diluted to a density equivalent to No. 10 Brown opacity tube. Agglutination tests were carried out in $\frac{1}{2}$-in. wide round-bottom tubes. One drop of the concentrated suspension was added to $0.5 \mathrm{ml}$. of each serum dilution and the tubes were incubated for two hours at $37^{\circ} \mathrm{C}$., left in the refrigerator overnight, and read 
two hours after removal next morning. Parallel tests, using Dreyer's technique and incubating the suspension for 24 hours at $56^{\circ} \mathrm{C}$., gave similar results. For absorption, serum diluted 1:10 was poured over the centrifuged deposit of a dense suspension of the absorbing organism and thoroughly mixed. The mixture of serum and bacteria was incubated for two hours at $37^{\circ} \mathrm{C}$. followed by 20 hours at refrigerator temperature $\left(+5^{\circ} \mathrm{C}\right.$. $)$.

In preparing $\mathrm{O}$ antisera it was necessary to take special precautions in order to obtain suitable heatkilled antigens. Many authors have noted the tendency of Pasteurella pseudotuberculosis to agglutinate spontaneously in normal saline, especially when the suspension is heated. Recommendations to overcome this difficulty include reduction of salt content to $0.3 \%$ (Topping, Watts, and Lillie, 1938), strong shaking of the suspension before boiling (Preston and Maitland, 1952 ), and the use of cultures grown at $22^{\circ} \mathrm{C}$. (Knapp, 1956). By using a combination of these methods we were able to obtain stable heat-killed suspensions. Smooth colonies of a $22^{\circ} \mathrm{C}$. culture were sown on tryptose agar and incubated at $22^{\circ}$ C. for 24 hours. The growth was harvested in $0.5 \%$ saline, agitated with glass beads in a shaker for 20 minutes, washed well in $0.5 \%$ saline, shaken again, and then exposed to flowing steam in a Koch sterilizer for two and a half hours or autoclaved at $120^{\circ} \mathrm{C}$. for two hours; $0.25 \%$ phenol was added as a preservative.

Agglutination Tests with Patients' Sera.-Preliminary slide agglutination tests indicated that agglutinins to Types IA and IB were present in the sera of all three patients. No agglutination was observed with the other serotypes. Because only limited amounts of sera were available tube agglutination tests had to be restricted to reactions with the Burke and Schofield strains and the National Collection of Type Cultures serotypes IA and IB. The results of the agglutination tests with unabsorbed and absorbed sera shown in Table II suggest that the Schofield and Burke strains are antigenically similar and probably belong to Type IA. The results with Sturgeon's serum also indicate infection with Pasteurella pseudotuberculosis Type I, but because of the relatively low titres obtained with the unabsorbed serum, we are unable to demonstrate residual titres after absorption with the four antigens.

Typing of Schofield and Burke Strains. - Typing of both strains was confined to the identification of the somatic factors present. Recognition of the flagellar antigen is of little value in the determination of the different types because, with the exception of Type IV, the antigen is common to all members of the group. $O$ agglutinating antisera were prepared in rabbits for Types IA and IB as well as for Schofield and Burke strains. Autoclaved antigen was inoculated intravenously in six doses $(0.25 \mathrm{ml} ., 0.5 \mathrm{ml} ., 1 \mathrm{ml}$., $1 \mathrm{ml}$., $1 \mathrm{ml}$., $1 \mathrm{ml}$.) at four-day intervals. The animals were bled on the twenty-eighth day. The results of

TABLE II

RESULTS OF AGGLUTINATION TESTS WITH ABSORBED AND UNABSORBED PATIENTS' SERA

\begin{tabular}{|c|c|c|c|c|c|}
\hline \multirow{3}{*}{ Sera } & & \multirow{2}{*}{\multicolumn{4}{|c|}{$\begin{array}{c}\begin{array}{c}\text { Agglutination Titres of Sera against } \\
\text { Four Strains of } \\
\text { Past. pseudotuberculosis }\end{array} \\
\text { Agglutinating Antigens }\end{array}$}} \\
\hline & & & & & \\
\hline & & Schofield & Burke & Type IA & Type IB \\
\hline $\begin{array}{l}\text { Schofield serum } \\
\text { Unabsorbed } \\
\text { Absorbed with } \\
\text { Schofield strain.. } \\
\begin{array}{l}\text { Burke strain } \\
\text { Type IA }\end{array} \\
\begin{array}{l}\text { Type IB } \\
\text { Type }\end{array} \\
\text {. . }\end{array}$ & $\begin{array}{l}\cdots \\
\cdots \\
\cdots \\
\cdots\end{array}$ & $\left\{\begin{array}{l}500 \\
<25 \\
25\end{array}\right.$ & $\left\{\begin{array}{r}500 \\
<25 \\
25\end{array}\right.$ & $\left\{\begin{array}{r}500 \\
<25 \\
25\end{array}\right.$ & $\begin{array}{r}500 \\
<25\end{array}$ \\
\hline $\begin{array}{l}\text { Burke serum } \\
\text { Unabsorbed } \\
\text { Absorbed with } \\
\text { Schofield strain. } \\
\begin{array}{l}\text { Burke strain } \\
\text { Type IA }\end{array} \\
\begin{array}{l}\text { Type IB } \\
\text { Ty }\end{array}\end{array}$ & $\begin{array}{l}\cdots \\
\cdots \\
\cdots \\
\cdots\end{array}$ & $\left\{\begin{array}{l}5,000 \\
<25 \\
200\end{array}\right.$ & $\left\{\begin{array}{l}5,000 \\
<25 \\
200\end{array}\right.$ & $\left\{\begin{array}{l}3,000 \\
<25 \\
200\end{array}\right.$ & 3,000 \\
\hline 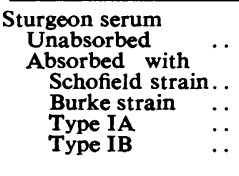 & $\begin{array}{l}\cdots \\
\cdots \\
\cdots\end{array}$ & $<25$ & $<25$ & $<25$ & $<25$ \\
\hline
\end{tabular}

TABLE III

RESULTS OF AGGLUTINATION TESTS WITH ABSORBED AND UNABSORBED RABBIT ANTISERA

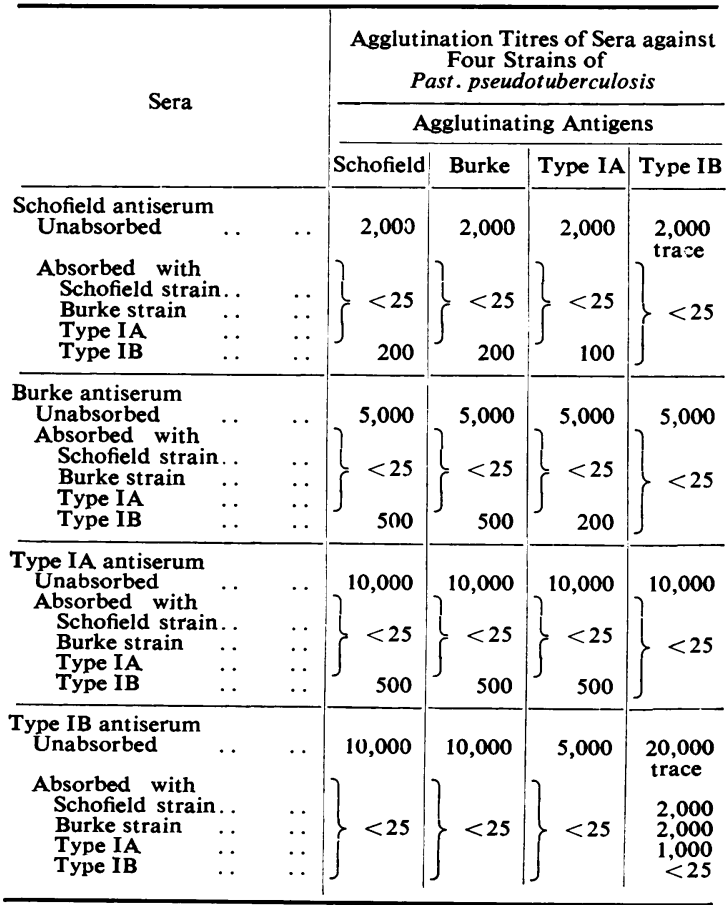


the cross-absorption tests show that the Schofield and Burke strains are antigenically similar to Type IA, thus confirming the findings made with the patients' sera (Table III). Both strains were later sent to Professor Knapp, of Tübingen, who kindly informed us that they belonged to Type IA.

Post-operative Decline in Antibody Titres.Serum taken from Schofield and Sturgeon five months after operation showed no evidence of agglutinins to Pasteurella pseudotuberculosis.

Burke's serum showed a rise in antibody titre two weeks after operation, but thereafter there was a steady decline until agglutinins had all but disappeared five months after onset of the illness (Table IV).

TABLE IV

RESULTS OF AGGLUTINATION TESTS WITH BURKE'S SERA SHOWING DECLINE IN ANTIBODIES

\begin{tabular}{c|c}
\hline Day after Onset of Illness & Serum Titre \\
\hline 4 th & 5,000 \\
17 th & 10,000 \\
33 rd & 2,000 \\
77 th & 500 \\
160 th & 25 trace \\
\hline
\end{tabular}

Antibiotic Sensitivity Tests.-These were carried out on the Schofield and Burke strains by the flood plate technique using "multodisk" (Oxoid) paper discs. Both cultures were fully sensitive to chloramphenicol $(10 \mu \mathrm{g}$.$) , streptomycin (10 \mu \mathrm{g}$.$) , tetracycline (10 \mu \mathrm{g}$.$) ,$ polymyxin $\mathrm{B}(10 \mu \mathrm{g}$.), neomycin $(10 \mu \mathrm{g})$, and nitrofurantoin $(200 \mu \mathrm{g}$.). Resistance was shown to penicillin $(1.5 \mu \mathrm{g}$.), erythromycin $(10 \mu \mathrm{g}$.), oleandomycin $(5 \mu \mathrm{g}$.), novobiocin (5 $\mu \mathrm{g}$.), bacitracin (5 units), and sulphafurazole $(100 \mu \mathrm{g}$.).

\section{Histology}

Biopsy specimens of appendices and mesenteric glands were fixed in formol saline and embedded in paraffin wax. Sections were stained with haematoxylin and eosin.

Case 1 (Sturgeon). - In the appendix there was no evidence of inflammation. The lymphoid follicles were large with prominent Flemming centres.

In the lymph node there was considerable sinus hyperplasia and the follicles showed well-defined centres. Towards the periphery of the node there was a single small follicle consisting of a group of polymorphonuclear pus cells and swollen cells resembling reticulum cells. The latter were quite large and an occasional cell appeared to have two nuclei. It was a very unusual type of follicle to be seen within a lymph node (Figs. 1 and 2). No organisms could be seen in Gram-stained, Cook-stained, or Ziehl-Neelsen-stained sections.
Case 2 (Schofield). - In this case the lymphoid follicles formed an almost continuous band around the lumen of the appendix and there was a plasma cell infiltration of the mucosa itself. Within the lumen of the appendix there was granular debris, containing fairly large numbers of lymphocytes, and a smear taken from this debris showed a large number of Gram-negative diplobacilli. They were also to be seen within the lymphoid follicles. No lymph node was examined in this case.

Case 3 (Burke).-In the appendix in this case, lymphoid follicles were very prominent and they tended to be two or three layers in depth.

Sinus hyperplasia in the lymph node was distinct. In this instance there were two follicles which appeared to be slightly later in stage than the one observed in Case 1 (Sturgeon). The follicles showed central necrosis with the presence of eosinophilic-staining debris. This necrotic area was infiltrated with plasma cells and polymorphs. It was surrounded by a layer of reticulum-cells showing somewhat haphazard palisading about four cells in depth. Beyond it the reticulum cells showed no orderly arrangement. In this outee zone there was an occasional foreign-body type of giant cell, polymorph and lymphocyte (Figs. and 4). No organisms could be seen in Gram stained, Cook-stained, or Ziehl-Neelsen-stained sections.

The lesions noted in the lymph glands were not found in the lymphoid follicles of any of the appendices.

\section{Discussion}

Until a few years ago human infection with Pasteurella pseudotuberculosis was generally regarded as rare. The first authentic case was described by Albrecht (1910). During the period between 1910 and 1952 some 15 cases were reported in the medical literature. Of these, 13 were characterized by a severe typhoid-like illness which terminated fatally in 11 cases.

In contrast to this rare septic type of infection the more frequent benign appendiceal form is now recognized. In addition to numerous cases mentioned in the German literature, other cases have been reported in Hungary (Podhragyai and Fodor, 1956) and in France (Ingelrans, Soots, Poupard, and Vitse, 1957 ; Girard, Leger, Paulhet, and Duffau, 1959). No cases appear to have been recorded in the English language.

This new disease complex shows a predilection for children and young people ( 2 to 23 years) and occurs more often in males than in females. The clinical picture is that of acute or subacute 


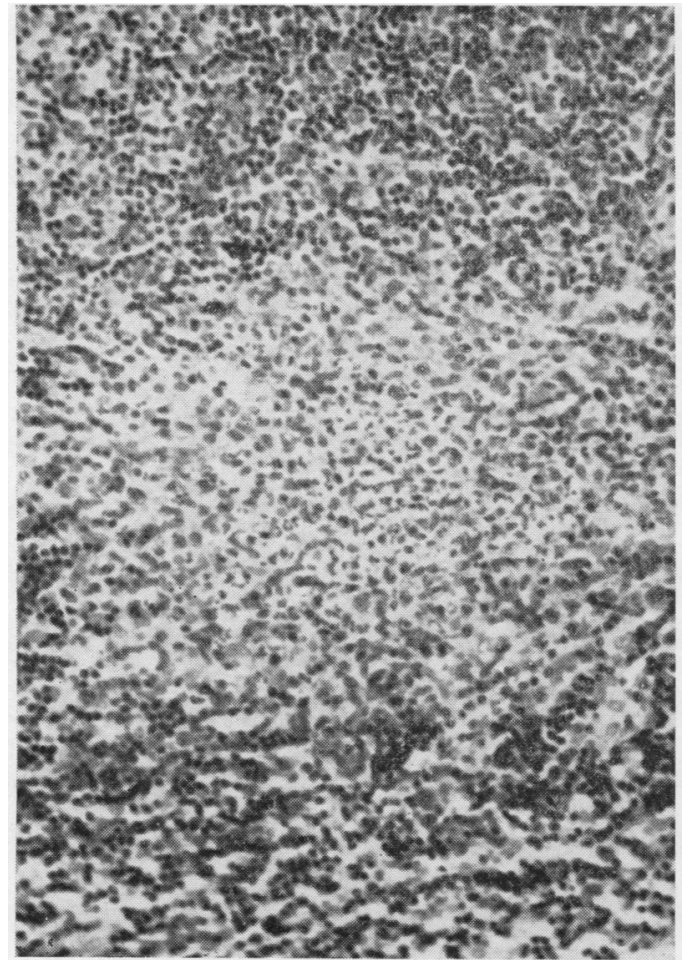

FIG. 1.-Case 1: Follicle consisting of swollen reticulum cells. The centre of the follicle is infiltrated with polymorphs. (Haematoxylin and $\operatorname{cosin} \times 150$.)

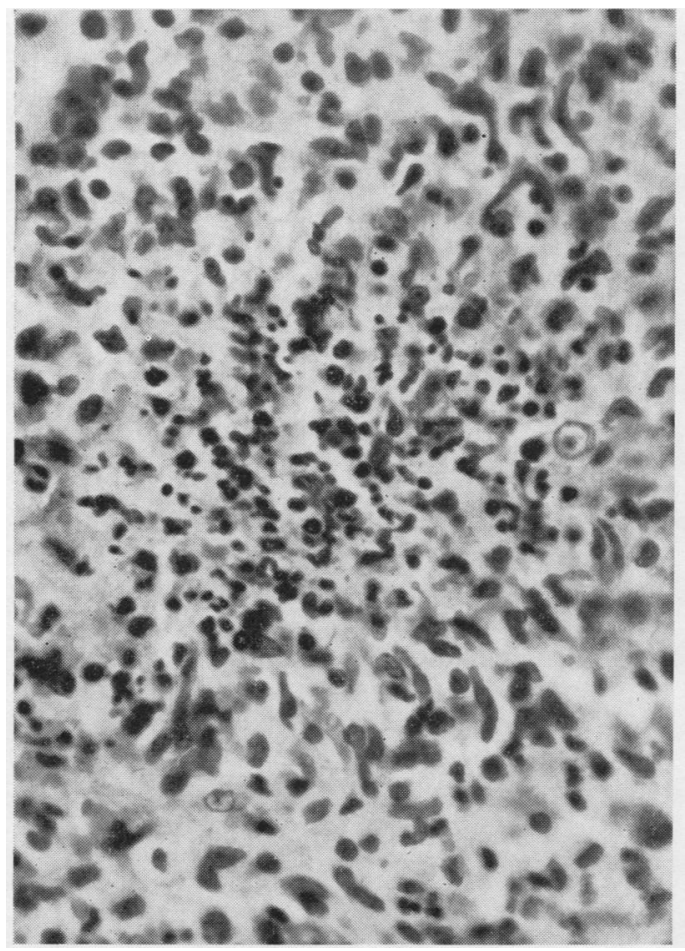

FIG. 3-Case 3: Follicle showing haphazard palisading of reticulum cells and area of central necrosis infiltrated with polymorphs. (Haematoxylin and eosin $\times 350$.)

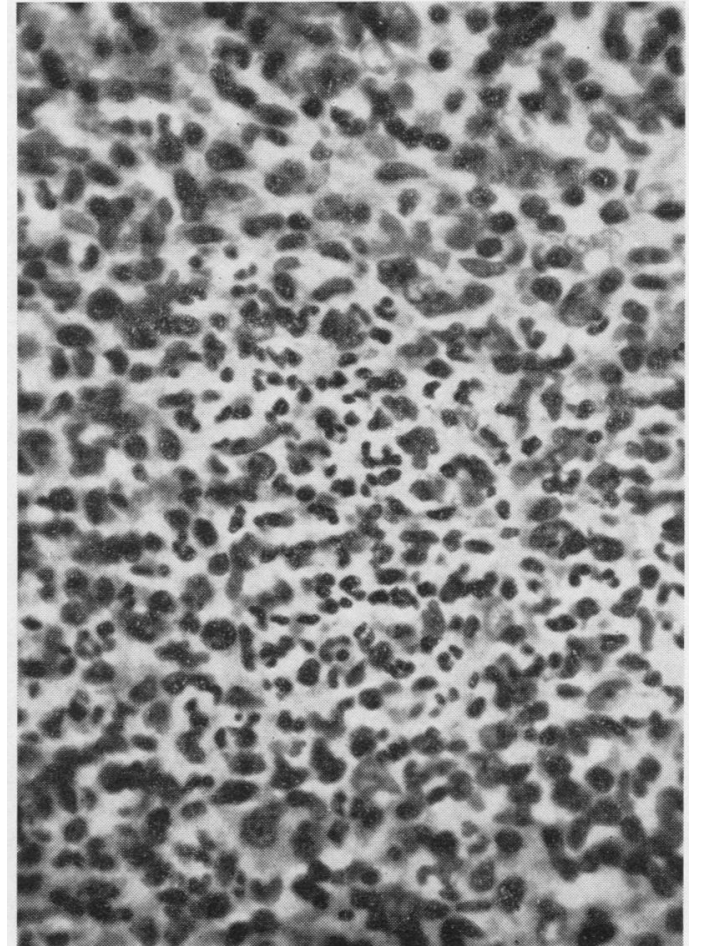

Fig. 2.-Case 1: Centre of follicle. (Haematoxylin and $\operatorname{cosin} \times 425$.)

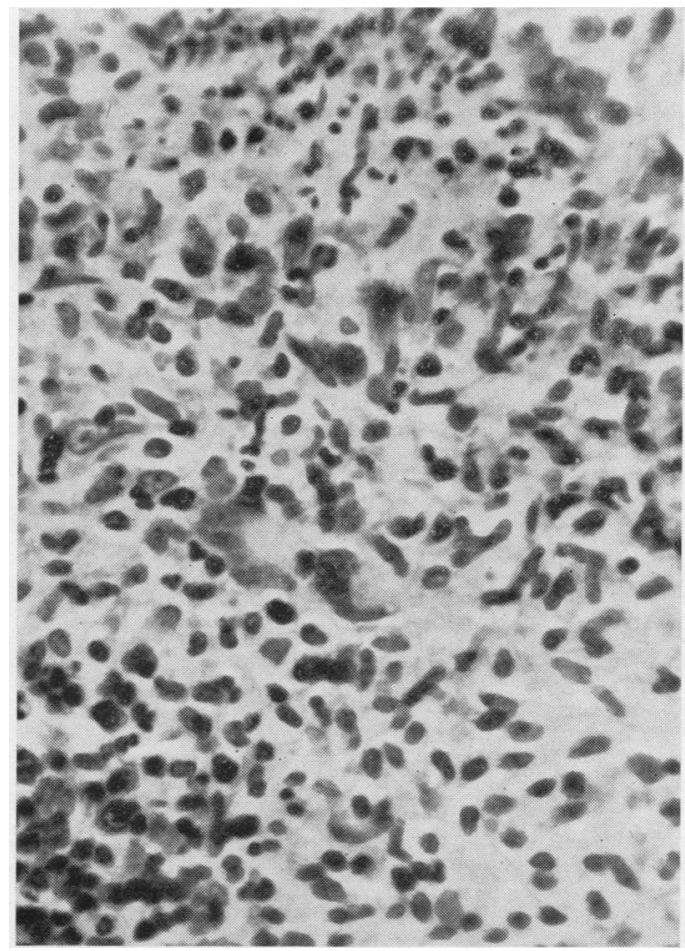

Fig. 4.-Case 3: Foreign-body type of giant cells in marginal zone of reticulum cells. (Haematoxylin and eosin $\times 350$.) 
appendicitis with pain in the middle or right lower quadrant of the abdomen. The temperature is elevated to $100^{\circ}$ or even higher, and there is invariably a leucocytosis. Laparotomy shows, in most cases, a normal-looking appendix. The lymphatic glands in the ileocaecal angle and in the mesentery are enlarged either singly or in groups. The peritoneum over the lymph nodes is congested and a clear or slightly purulent exudate is often present. Inflammatory infiltration of the terminal ileum has also been described.

In our first two cases there was some preoperative doubt as to the correct diagnosis, but both patients were too unwell to justify withholding an exploratory laparotomy. The third case (Burke) was considered by his own doctor to have mesenteric adenitis, but on admission his symptoms and signs were such that there seemed to be no doubt about the diagnosis of acute appendicitis.

The findings at operation on all three patients were essentially similar. After the first two had been seen-and the diagnosis of pasteurella infection subsequently established - the third case was strongly suspected at operation and later confirmed pathologically. In all three it was obvious that the appendix was not the cause of the trouble ; such exploration as could be carried out through a muscle-splitting incision failed to reveal any abnormality other than in the affected ileocaecal glands. Owing to the limited exposure obtained, the extent of the glandular enlargement could not be determined. Suppuration was not seen in any of the three cases and there was no gross oedema of the mesentery around any of the affected nodes. Peritoneal exudate was not observed.

The naked-eye appearance of the glands suggests that it may be possible to distinguish between those cases due to infection with Pasteurella pseudotuberculosis and those due to other causes. The glands seen in the nonpasteurella group appear to be pale, flattened rather than round, and uniformly enlarged. In our three cases associated with pasteurella infection the glands were dark in colour with one or two white streaks across the surface, almost round, and variable in size, the largest being about the size of a cherry and the smallest no bigger than a dried pea. All were firm, not hard, fixed within the mesentery but not adherent to it. Removal was easy and there was no undue tendency to bleeding.

The definitive diagnosis, however, is established by the isolation of the organism from the lymphatic glands, by the demonstration of specific antibodies in the serum, and through histological examination of the lymph nodes.

Pasteurella pseudotuberculosis is not readily isolated from infected glands. Only 12 of the 117 cases mentioned by Knapp, and one of nine cases reported by Schmidt (1959), were confirmed by isolation of the organism from the lymph nodes. That incubation at $37^{\circ} \mathrm{C}$. may not be sufficient is shown by the behaviour of Burke's strain, which was isolated only after preliminary incubation in broth at $22^{\circ} \mathrm{C}$. Identification of the organism itself is not difficult. Its motility in 18-hour broth cultures at $22^{\circ} \mathrm{C}$., its ability to grow on MacConkey medium and to decompose urea, and the caseous nodules produced in guineapigs after experimental inoculation, help to distinguish it from other members of the pasteurella group.

Antibodies to Pasteurella pseudotuberculosis can be demonstrated in the blood during the acute phase of the illness. By means of agglutination tests with live, smooth variants of Pasteurella pseudotuberculosis Types $\mathrm{I}-\mathrm{V}$, titres of $1: 80$ to $1: 12,800$ have been recorded. In our own cases titres varied from $1: 300$ on the sixth day of Sturgeon's illness to $1: 5,000$ on the fourth day o $\$$ Burke's attack. The tests are specific only fot Types I, III, and V. The specificity of the agglutination test for Types II and IV is affected by the antigenic relationships which exist between Pasteurella pseudotuberculosis Type II and factor IV of the salmonella B group and Pasteurella pseudotuberculosis Type IV and factor IX of the salmonella D group (Kauffmann, 1933 ; Knapp, 1955). These give rise to fairly strong crossreactions. In order that a serological diagnosis can be made it is necessary to absorb the patient's serum with the corresponding strain of the $B$ or D group. However, such absorptions are not often necessary, since more than $90 \%$ of pseudotuberculous infections in man are caused by Pasteurella pseudotuberculosis Type I. The specificity of the agglutination test was confirmed by Knapp (1956), who was unable to find antibodies against Pasteurella pseudotuberculosis in the blood of 76 children with typical appendicitis. In 1,601 sera obtained for Wassermann and Widal tests he found antibodies to Types I, III, and V in only nine patients, all of whom gave a history suggestive of mesenteric adenitis. If complications do not occur, agglutinins disappear within a few months. All our three cases, who remained well after operation, showed little or no antibody in the blood five months later. In Burke's case there was a rise in titre a fortnight after operation. Two and a half months later the titre had fallen 
considerably, and at the end of five months only a trace reaction was obtained with a serum dilution of $1: 25$.

The histological findings confirm the observation made by Knapp and Masshoff (1954). In our third case, the appearance of the two abnormal follicles consisting of reticulum cells with central necrosis was most striking. The arrangement of the reticulum cells around the periphery of the necrotic area was much more haphazard than one sees in sarcoidosis, and the central eosinophilic tissue did not resemble caseation of tubercle. The same phenomenon was observed in Case 1, but to a lesser degree. These changes are not specific for pseudotuberculosis since they have also been observed in tularaemia, lymphogranuloma inguinale, and cat-scratch fever. Nevertheless, they appear to be a characteristic feature of infection with Pasteurella pseudotuberculosis and were noted by Knapp (1959) in $86 \%$ of his cases.

The epidemiology of human pseudotuberculosis remains obscure. Pasteurella pseudotuberculosis is known to cause epizootics in guinea-pigs and turkeys, and sporadic infections have been reported in rabbits and hares, cattle, chickens, goats and pigs, cats and dogs, pigeons, canaries, sparrows, and blackbirds. It has not been possible to relate human cases to contact with domestic animals or to the use of their products. In the present cases the only history of contact with animals was that a budgerigar was kept by the Burke family and that 12 days before the boy was taken ill the bird sickened and remained off-colour for seven days, when it recovered, apparently without any ill effects. It was not possible to obtain the bird for examination, but droppings from the cage were cultured for Pasteurella pseudotuberculosis with negative results.

Little has been reported on the treatment of human pseudotuberculosis. Four cases of the severe septic type of infection were treated with sulphonamides and antibiotics and two of them survived (Knapp, 1959). Although antibiotics have been used for the treatment of the benign appendiceal form and as a prophylactic measure to prevent possible post-operative complications, it is difficult to assess their value, as most of these cases run a benign course, and those treated surgically usually make an uneventful recovery. Should the administration of antibiotics be considered necessary, the results of tests in vitro suggest that the broad-spectrum antibiotics would be the drugs of choice.

It is evident from the results of this investigation that pseudotuberculous mesenteric adenitis occurs in this country as well as on the Continent. While the definitive diagnosis rests on the isolation of the organism from the lymphatic glands the possibility of adhesions arising from routine gland biopsy must be taken into consideration (Aird, 1958). In those cases where biopsy is deemed inadvisable, or where provisional diagnosis of acute mesenteric adenitis is made, it may be possible to arrive at a diagnosis in many cases of pasteurella infection by carrying out agglutination tests with the patient's serum against the five serotypes of Pasteurella pseudotuberculosis.

The investigation would not have been possible but for the interest of the consultant surgeons at the Leicester Royal Infirmary and the Leicester General Hospital; all kindly agreed to their patients with mesenteric adenitis being included in the survey. For access to the records of Cases 1 and 2 we are indebted to Mr. D. McGavin, and for Case 3 to Mr. E. R. Frizelle.

Dr. E. Milford Ward's observations on the histological findings were of considerable value in confirming the diagnoses. We are especially grateful to Mr. B. J. Fowler for his interest and advice.

\section{REFERENCES}

Aird, I. (1945). Brit. med. J., 2, 680.

(1958). A Companion in Surgical Studies. Livingstone,

Albrecht, H. (1910). Wien. klin. Wschr., 1910, 991.

Cook, R. (1952). J. Path. Bact., 64, 228.

Felsen, J. (1935). Amer. J. Dis. Child., 50, 661.

Girard, G., Leger, H., Paulhet, J., and Duffau, A. (1959). Presse méd., 67, 249 .

Ingelrans, Soots, Poupard, and Vitse (1957). Lille chir., 12, 201.

Kauffmann, F. (1933). Z. Hyg. Infekt.-Kr., 114, 97.

Kirthi Singha, H. S. (1959). Brit. med. J., 2, 220

Knapp, W. (1954). Zbl. Bakt., I. Abt. Orig., 161, 422.

- (1955). Ibid., 164, 57

(1956). Z. Hyg. InfektKr., 143, 261

(1958). New Engl. J. Med., 259, 776.

(1959). Ergebn. Mikrobiol., 32, 196.

- and Masshoff, W. (1954). Dtsch. med. Wschr., 79, 1266

Masshoff, W., and Dölle, W. (1953). Virchows Arch. path. Anat., 323,664 .

Podhragyai, L., and Fodor, I. (1956). Orv. Hetil., 97, 277.

Preston, N.W., and Maitland, H. B.(1952). J. gen. Microbiol., 7, 117. Schmidt, J. (1959). Arch. Hyg. (Berl.), 143, 262.

Topping, N. H., Watts, C. E., and Lillie, R. D. (1938). Publ. Hlth Rep. (Wash.), 53, 1340.

Westwood, J. C. N., Macpherson, I. A., and Titmuss, D. M. J. (1957). Brit. J. exp. Path., 38, 138. 